\title{
Best performances by men and women open-water swimmers during the 'English Channel Swim' from 1900 to 2010
}

Eichenberger, Evelyn ; Knechtle, Beat ; Knechtle, Patrizia ; Rüst, Christoph Alexander ; Rosemann, Thomas ; Lepers, Romuald

Abstract: Abstract Little research has examined ultra-endurance swimming performances. The 'English Channel Swim', where swimmers have to cover a distance of $32 \mathrm{~km}$ between England and France represents a unique longdistance, open-water, sea-swimming challenge, and each year swimmers from all over the world try to succeed in this challenge. The best times in minutes and the nationality of successful men and women swimmers were analysed from 1900 to 2010. A total of 1,533 swimmers ( 455 women and 1,078 men) from more than 40 countries have successfully completed the 'English Channel Swim'. Great Britain was the country most represented, with $38 \%$ of the total, followed by the United States with $20 \%$. Swim speed has increased progressively for both sexes (P $<0.001)$ but was lower for women than for men $(0.68 \pm 0.15 \mathrm{~m} \cdot \mathrm{s}(-1) \mathrm{vs} 0.71 \pm 0.16 \mathrm{~m} \cdot \mathrm{s}(-1)$ respectively, $\mathrm{P}<0.01)$. However, the best annual performances did not differ between the sexes (men: $0.89 \pm 0.20 \mathrm{~m} \cdot \mathrm{s}(-1)$; women: $0.84 \pm$ $0.18 \mathrm{~m} \cdot \mathrm{s}(-1), \mathrm{P}>0.05)$. The results suggest that the performance of women open-water ultra-distance swimmers may be similar to that of men. Further studies investigating anthropometrical and physiological characteristics of open-water ultra-swimmers are needed to compare men's and women's open-water ultra-swim performances.

DOI: https://doi.org/10.1080/02640414.2012.709264

Posted at the Zurich Open Repository and Archive, University of Zurich ZORA URL: https://doi.org/10.5167/uzh-64218

Journal Article

Accepted Version

Originally published at:

Eichenberger, Evelyn; Knechtle, Beat; Knechtle, Patrizia; Rüst, Christoph Alexander; Rosemann, Thomas; Lepers, Romuald (2012). Best performances by men and women open-water swimmers during the 'English Channel Swim' from 1900 to 2010. Journal of Sports Sciences, 30(12):1295-1301.

DOI: https://doi.org/10.1080/02640414.2012.709264 
Best performances by men and women open-water swimmers during the “English Channel Swim" from 1900 to 2010

Running title: 'English Channel Swim' performances from 1900 to 2010 


\begin{abstract}
Little research has examined ultra-endurance swimming performances. The 'English Channel Swim', where swimmers have to cover a distance of $32 \mathrm{~km}$ between England and France represents a unique long-distance, open-water, sea-swimming challenge, and each year swimmers from all over the world try to succeed in this challenge. The best times in minutes and the nationality of successful men and women swimmers were analysed from 1900 to 2010. A total of 1,533 swimmers (455 women and 1,078 men) from more than 40 countries have successfully completed the 'English Channel Swim'. Great Britain was the country most represented, with $38 \%$ of the total, followed by the United States with $20 \%$. Swim speed has increased progressively for both sexes $(P<0.001)$ but was lower for women than for men $\left(0.68 \pm 0.15 \mathrm{~m} \cdot \mathrm{s}^{-1}\right.$ vs $0.71 \pm 0.16 \mathrm{~m} \cdot \mathrm{s}^{-1}$ respectively, $\left.P<0.01\right)$. However, the best annual performances did not differ between the sexes (men: $0.89 \pm 0.20 \mathrm{~m} \cdot \mathrm{s}^{-1}$; women: $0.84 \pm 0.18 \mathrm{~m} \cdot \mathrm{s}^{-}$ $\left.{ }^{1}, P>0.05\right)$. The results suggest that the performance of women open-water ultra-distance swimmers may be similar to that of men. Further studies investigating anthropometrical and physiological characteristics of open-water ultra-swimmers are needed to compare men's and women's open-water ultra-swim performances.
\end{abstract}

Keywords: Athlete, nationality, extreme endurance, elite swimmer 


\section{Introduction}

In recent years, there has been an increased interest in participation and performance trends in ultra-endurance events, defined as those lasting more than six hours (Zaryski \& Smith, 2005). Participation and performance trends have been analysed in 161-km ultra-marathons (Hoffman, Ong, \& Wang, 2010), Ironman distance triathlons (Lepers, 2008; Lepers \& Maffiuletti, 2011) and ultra-triathlons of longer than the Ironman distance (Knechtle, Knechtle, \& Lepers, 2011). However, there are no data about participation and performance trends in open-water ultra-endurance swimming.

The 'English Channel Swim' between England and France is a unique long-distance openwater sea-swimming challenge where athletes have to cover $32 \mathrm{~km}$. The first person who officially swam the Channel was Matthew Webb from the United Kingdom in 1875 with a time of 21 h 45 min (www.dover.uk.com/channelswimming). His success inspired many swimmers to emulate his achievement, both at that time and up to the present day. The majority of swimmers swam from England to France, but some swam from France to England. The 'English Channel Swim' is an open-water swim where the athletes have to swim from Dover (England) to Calais (France) or from Calais to Dover, a distance of $\sim 32 \mathrm{~km}$, with often a strong tidal current. Generally, the Channel water temperature varies between 14 and $18{ }^{\circ}$ Celsius (www.channelswimmingassociation.com). Swimmers have to bring their own nutrition and organise accommodation by themselves. A support crew on a boat needs to be at the side of the swimmer during the whole event to ensure both safety and nutrition. The athletes can grease their bodies but are not allowed to wear protective or performanceenhancing swimsuits. It is also prohibited to use any facilities for propulsion. 
In contrast to pool swimming (Tanaka \& Seals, 1997; Trewin, Hopkins, \& Pyne, 2004), the performances and characteristics of open-water swimming are much less documented. Knechtle, Baumann, Knechtle and Rosemann (2010a) described the association of anthropometry and training with race performance in men open-water ultra-endurance swimmers. These authors showed that speed during training was moderately associated with total race time whereas anthropometry had no correlations. It has also been reported that specific anthropometric characteristics of open-water ultra-swimmers were associated with race time in men but not in women (Knechtle, Baumann, Knechtle, \& Rosemann, 2010b). In contrast, anthropometric characteristics were not related to race performance in men swimmers in a 12-hour ultra-endurance pool-swim (Knechtle, Knechtle, \& Kohler, 2008). Notably, VanHeest, Mahoney, and Herr (2004) examined physical and metabolic characteristics of elite-standard open-water swimmers and reported that these swimmers possessed aerobic metabolic alterations that resulted in an enhanced performance in longdistance swimming.

Men are faster than women in open-water long-distance swimming such as the $3.8 \mathrm{~km}$ swim split in an Ironman triathlon or the $3.8 \mathrm{~km}$ 'Waikiki Roughwater Swim Race' (www.wrswim.com), with a sex difference of $\sim 10-12 \%$ (Lepers, 2008; Lepers \& Maffiuletti, 2011). Swimming economy is higher in women than men (Lavoie \& Montpetit, 1986; Pendergast et al., 1977). Indeed, in contrast to running where oxygen cost is similar for both sexes, the energy cost of freestyle swimming is higher (i.e. lower economy) in men than women (Pendergast et al., 1977). The higher economy of women has been attributed to a smaller body size resulting in less body drag, a lower body density with a greater fat percent, and shorter lower limbs, resulting in improved horizontal and streamlined positions (Lavoie \& Montpetit, 1986; Pendergast et al., 1977). This higher economy of women could be an advantage in an ultra-swim performance. Therefore, it would be informative to analyze sex - 
based differences in an open-water ultra-endurance event such as the 'English Channel Swim', known as the world's ultimate long-distance swim.

The aims of the present study were $(i)$ to investigate the participation and performance trends in the 'English Channel Swim' from 1900 to 2010 and, (ii) compare men's and women's ultra-swim performances. 


\section{Materials and methods}

The time in minutes and the nationality of the men and women who have completed a crosschannel swim from 1900-2010 were obtained from the official, open-access web site www.dover.uk.com/channelswimming/swims. The times of the crossings, in both directions, were pooled. Swim times were converted to swimming speed $\left(\mathrm{m} \cdot \mathrm{s}^{-1}\right),($ Nevill \& White, 2005; Winter \& Fowler, 2009). While we investigated the overall performance trend, we also studied the performances of the athletes originating from different countries. This crosssectional study was approved by the Institutional Review Board of St. Gallen, Switzerland

\section{Statistical analysis}

After verification of underlying assumptions, data were reported as means \pm standard deviation. Linear regressions estimated annual changes of selected variables. Pearson's correlation coefficients assessed associations between various variables. A fully betweengroups factorial ANOVA (years x sex) compared swimming speeds between men and women across years. Tukey's post hoc analyses tested differences where appropriate. The women's and men's best annual swimming speed were compared with a Student's t-test during the studied period (Statsoft, Version 6.1, Statistica, Tulsa, OK, USA). Effect size was calculated by the Cohen's $d$ and was defined as small for $d=0.2$, medium for $d=0.5$ and large for $d=$ 0.8. All $P$-values were two-tailed and values below .05 were considered to indicate statistical significance. 


\section{Results}

\section{Participation trends}

From 1900 to 2010, 1533 (29.7\% women and 70.3\% men) swimmers completed the 'English Channel Swim'. The mean annual crossings was $15 \pm 15$ [range: $0-72]$ for men and $7 \pm 7$ [range: 0-29] for women, (Figure 1). The number of crossings regularly increased from 1950 to 2000, but the increase has become more pronounced since 2000 especially for men swimmers. The mean number of swimmers per decade increased between 1991-2000 and 2001-2010, by $171 \%$ for men and by $135 \%$ for women.

The swimmers came from more than 40 countries. Figure $\mathbf{2 A}$ shows the countries with the most successful Channel swimmers. The nation most represented was the United Kingdom (38\% for men and 39\% for women), followed by the United States (20\% and 22\% respectively) and then Australia (7\% and 5\% respectively). Figure 2B shows the nationalities having the best annual time performances, with Great Britain at 42 (25 men and 17 women), followed by the United States with 25 ( 8 men and 17 women) and Egypt with 11 ( 7 men and 4 women).

\section{Swimming performances}

There was a years $\mathrm{x}$ sex interaction for swimming speed $(\mathrm{F}=1.49 ; P=0.012)$ i.e. men improved more than women. There was main effect for speed with men swimming faster $(\mathrm{F}=$ 8.47; $P=0.004)$. Overall swimming speed was lower $(P<0.01)$ for women than men : $0.68 \pm 0.15 \mathrm{~m} \cdot \mathrm{s}^{-1}$ vs $0.71 \pm 0.16 \mathrm{~m} \cdot \mathrm{s}^{-1}$ respectively (Cohen's $d=0.19$ ). The trends of the best annual 'English Channel Swim' speeds both for men and women during this period are shown in Figure 3. The linear regressions showed that the swimming speed progressively increased 
$(P<0.001)$ for both sexes, by $0.06 \mathrm{~m} \cdot \mathrm{s}^{-1}$ per decade for women and $0.07 \mathrm{~m} \cdot \mathrm{s}^{-1}$ per decade for men.

Sex difference

Contrary to the general trend, the mean of the best annual 'English Channel Swim'

performances did not differ between men and women during the studied period (Figure 4) $(P$ $>0.05$; Cohen's $d=0.26$ ). When considering the Channel records in both directions, the sex differences in swimming speed account for 6.7\% England-to-France, and 8.9\% France-toEngland (Table 1). 


\section{Discussion}

The main findings in this study were $(i)$ an increase in participation in the 'English Channel Swim' over the last century, (ii) a progressive improvement in swimming performances , and (iii) in general, greater swimming speed for men than for women but no such sex-based difference in the best annual 'English Channel Swim' performances.

\section{Participation trends in the 'English Channel Swim'}

The number of ultra-swimmers participating in the 'English Channel Swim' has increased since 1900. In recent decades, more than 50 men and 20 women have successfully completed the 'English Channel Swim' each year. Women's participation represents $\sim 30 \%$ of the total field. In comparison, Hoffman et al. (2010) showed that the participation of women in 161-km ultra-marathons (20\%) was less than road-running races (49\%) and marathons (40\%). In another ultra-endurance event, the 'Ironman Hawaii' triathlon, the proportion of women participants reached $27 \%$ (of the 1,700 athletes) in 2007 (Lepers, 2008). One reason for the greater participation of men Channel swimmers could be their higher ego orientation compared with women (Hanrahan \& Cerin, 2009), since the 'English Channel Swim' represents a typical individual ultra-endurance challenge. Another reason could be that men generally take more risks and participate more frequently in dangerous activities than women (Butković \& Bratko, 2003).

Swimmers come from all over the world to tackle the 'English Channel Swim' and this high interest has not declined in either sex. The organiser advertises this event as the 'Everest' of swimming events. Challenges range from variable weather conditions such as wind force 6 and above, waves higher than two metres, cold water, congested shipping lanes, as well as jellyfish, seaweed and detritus such as planks of wood. Unfortunately, the 'English Channel Swim' has 
had six fatalities (www.dover.uk.com/channelswimming/fatalities.php). In comparison, 129 people have died when climbing 'Mount Everest' between 1980 and 2002 (Firth et al., 2008; Huey \& Salisbury, 2003). Approximately 8,494 people have tried to climb 'Mount Everest' during this time and, like the 'English Channel Swim', in more recent years participation has increased markedly although, nowadays, it has levelled off to 265 climbers per year. Of the 'Mount Everest' climbers, $\sim 1.5 \%$ has died, whereas the equivalent for the 'English Channel Swim' is $0.4 \%$. On 'Mount Everest', the rate of death is $\sim 4$ times higher than in the 'English Channel Swim'. A reason for this could be that when accidents happen, 'Mount Everest' rescuers have more difficulty reaching casualties than in the English Channel (Firth et al., 2008). Despite the well-known risks, many ultra-swimmers, worldwide, still intend to complete the 'English Channel Swim'. The increasing number of athletes participating in an event such as the 'English Channel Swim' could indicate that people are increasingly seeking a special thrill. However, costs such as entry fee, travel, accompanying pilot and boat could be prohibitive for many, and probably more would participate if the challenge was less expensive.

For participation from different nations, most swimmers $(\sim 38 \%)$ came from the United Kingdom, followed by the USA with $\sim 20 \%$. The high participation rate of UK swimmers could be because the most common crossing is from England to France, so UK swimmers are nearer to the Channel than other nationalities. Surprisingly, the number of athletes from France was low (less than 5\%). This might be because the French authorities prohibit swimmers starting from the French coast but allow swimmers coming from England (http://www.independent.co.uk/news/uk/this-britain/french-call-for-ban-on-channelswimming-2122612.html). Besides France and the UK, swimmers from over 40 other countries such as Ireland, Egypt and India have participated in this event. A reason for athletes coming from countries far away from the UK could be that the 'English Channel Swim' is a prestigious swimming event. Additionally, it could be that interest for open-water 
ultra-endurance swimming is because these countries are maritime. Costs are influential because athletes must have financial resources so tend to originate from wealthy countries.

\section{Performance trends at the 'English Channel Swim'}

In addition to having the greatest participation rate, the United Kingdom also had the greatest number of best annual 'English Channel Swim' performances with 42 during the last century. With the number of participants over the years, UK ultra-swimmers could gain more experience than athletes from other countries, which could be an advantageous. In contrast to our findings, Trewin et al. (2004) showed that US swimmers were 1.8\% faster than swimmers from other nations in the Olympic Games 2000. However, these authors investigated results from professional swimmers in indoor-pool competitions, while the 'English Channel Swim' can be considered as a non-professional open-water ultra-endurance event.

\section{Sex-based differences in the 'English Channel Swim'}

Swim speed increased for both sexes during the studied period, which supported with our hypothesis. The athletes improved their ultra-swim performance presumably by modifying their pre-race preparation, training, and other factors such as equipment and nutrition (Knechtle et al. 2010a; Tanaka \& Seals, 2008; Zaryski \& Smith, 2005). The difference between the sexes in the 'English Channel Swim' performance was 7-9\% in favour of men for the record time. However, the present study showed that the best annual swim performances did not differ between the sexes. This suggests that on the whole, the performance of women ultra-swimmers is similar to that of men. This observation supports the finding of Tanaka and Seals (1997) that sex-based differences in performance is less in long-distance swimming events than short- distance ones (Tanaka \& Seals, 1997). It has been suggested that women swimmers have a greater economy than men (Lavoie \& Montpetit, 1986; Pendergast et al., 1977). This characteristic could be advantageous in an ultra-swim performance. In addition, 
sex-based metabolic differences during prolonged exercise, specifically, a greater capacity for lipid oxidation, could allow women to maintain normoglycaemia and preserve muscle glucose in long-duration events (Blaak, 2001; Froberg \& Pedersen, 1984; Tarnopolsky, 2000). Therefore, women would have an advantage over men in endurance events when glycogen stores are low.

Water temperature varies between $14{ }^{\circ} \mathrm{C}$ and $18{ }^{\circ} \mathrm{C}$ in the 'English Channel Swim', and it has been shown that swimmers can stay longer in cold water when they have more body fat (Acevedo, Meyers, Hayman, \& Haskin, 1997; Keatinge, Khartchenko, Lando, \& Lioutov, 2001; Knechtle, Christinger, Kohler, Knechtle, \& Rosemann, 2009) because fat is a better insulator than skeletal muscle for open-water ultra-endurance swimmers (Hatfield \& Pugh, 1951). Women tend to have more body fat, therefore, could have an advantage in longduration swimming events in cold water (Knechtle et al. 2010b; Pugh \& Edholm, 1955). In addition, the higher body fat of women is advantageous for swimming because of the increased buoyancy (Hatfield \& Pugh, 1951). Another reason could be the effect of gravity on inclinations that influences cycling and in particular running but not swimming (Lynch \& Hoch, 2010; Tanaka \& Seals, 1997). However, it has also been shown that in open-water ultra-endurance swimmers, only the swimming speed during training was related to performance in women, whereas body mass, length of arms, stature and speed during training were also related to performance in men (Knechtle et al., 2010b).

\section{Conclusion}

The number of athletes participating in the 'English Channel Swim' has increased since 1900, especially from 2000 to 2010, despite many life-threatening factors such as storms, high waves and cold water. The United Kingdom has provided most participants and the greatest number of best annual 'English Channel Swim' performances. The best annual performances 
did not differ between the sexes. This suggests that women ultra-swimmers are capable of similar performances to men during open-water ultra-swim events. Further studies investigating anthropometrical and physiological characteristics of open-water ultraswimmers are needed to gain better insights into sex-based differences and similarities in open-water ultra-swim performances.

Acknowledgments: We thank Mary Miller for her help in translation. 


\section{References}

Acevedo, E. O., Meyers, M. C., Hayman, M., \& Haskin, J. (1997). Applying physiological principles and assessment techniques to swimming the English Channel. A case study. Journal of Sports Medicine and Physical Fitness, 37, 78-85.

Blaak, E. (2001). Gender differences in fat metabolism. Current Opinion in Clinical Nutrition and Metabolic Care, 4, 499-502.

Butković, A., \& Bratko, D. (2003). Generation and sex differences in sensation seeking: results of the family study. Perceptual and Motor Skills, 97, 965-970.

Firth, P. G., Zheng, H., Windsor, J. S., Sutherland, A. I., Imray, C. H., Moore, G. W., Semple, J. L., Roach, R. C, \& Salisbury, R. A. (2008). Mortality on Mount Everest, 1921-2006: descriptive study. BMJ, 337, a2654.

Froberg, K., Pedersen, P. K. (1984) Sex differences in endurance capacity and metabolic response to prolonged, heavy exercise. European Journal of Applied Physiology and Occupational Physiology, 52, 446-450.

Hanrahan, S. J., \& Cerin, E. (2009). Gender, level of participation, and type of sport: Differences in achievement goal orientation and attributional style. Journal of Science and Medicine in Sport, 12, 508-512.

Hatfield, H. S., \& Pugh, L. G. C. (1951). Thermal conductivity of human fat and muscle. Nature, 168, 918-919.

Hoffman, M. D., Ong, J. C., \& Wang, G. (2010). Historical analysis of participation in 161 $\mathrm{km}$ ultramarathons in North America. International Journal of the History of Sport, 27, 1877-1891.

Huey, R. B., \& Salisbury, R. (2003). Success and death on Mount Everest. American Alpine Journal, 287, 1ą10.

Keatinge, W. R., Khartchenko, M., Lando, N., \& Lioutov, V. (2001). Hypothermia during sports swimming in water below $11^{\circ} \mathrm{C}$. British Journal of Sports Medicine, 35, 352353.

Knechtle, B., Baumann, B., Knechtle, P., \& Rosemann, T. (2010a). What influences races performance in male open-water ultra-endurance swimmers: anthropometry or training? Human Movement, 11, 91-95.

Knechtle, B., Baumann, B., Knechtle, P., \& Rosemann, T. (2010b). Speed during training and anthropometric measures in relation to race performance by male and female openwater ultra-endurance swimmer. Perceptual and Motor Skills, 111, 463-474.

Knechtle, B., Christinger, N., Kohler, G., Knechtle, P., \& Rosemann, T. (2009). Swimming in ice cold water. Irish Journal of Medical Sciences, 178, 507-511. 
Knechtle, B., Knechtle, P., \& Kohler, G. (2008). No correlation of anthropometry and race performance in ultraendurance swimmer at a 12-hour-swim. Anthropologischer Anzeiger, 66, 73-79.

Knechtle, B., Knechtle, P., \& Lepers, R. (2011). Participation and performance trends in ultratriathlons from 1985 to 2009. Scandinavian Journal of Medicine and Science in Sports, 21, e82-90.

Lavoie, J. M., \& Montpetit, R. R. (1986). Applied physiology of swimming. Sports Medicine, $3,165-189$.

Lepers, R. (2008). Analysis of Hawaii Ironman performances in elite triathletes from 1981 to 2007. Medicine and Science in Sports and Exercise, 40, 1828-1834.

Lepers, R., \& Maffiuletti, N. A. (2011). Age and gender interactions in ultraendurance performance: insight from the triathlon. Medicine and Science in Sports and Exercise, $43,134-139$.

Lynch, S. L., \& Hoch, A. Z. (2010). The female runner: gender specifics. Clinics in Sports Medicine, 29, 477-498.

Nevill, A. M., \& White, G. (2005). Are there limits to running world records? Medicine and Science in Sports and Exercise, 37, 1785-1788.

Pendergast, D. R., Di Prampero, P. E., Craig, A. B., Wilson, D. R., \& Rennie, D. W. (1977). Quantitative analysis of the front crawl in men and women. Journal of Applied Physiology, 43, 475-479.

Pugh, L. G. C., \& Edholm, O. G. (1955). The physiology of Channel swimmers. Lancet, 2, 761-768.

Tanaka, H., \& Seals, D. (1997). Age and gender interactions in physiological functional capacity: insight from swimming performance. Journal of Applied Physiology, 82, 846-851.

Tanaka, H., \& Seals, D. R. (2008). Endurance exercise performance in masters athletes: ageassociated changes and underlying physiological mechanisms. The Journal of Physiology, 586, 55-63.

Tarnopolsky, M. A. (2000). Gender differences in metabolism, nutrition and supplements. Journal of Science and Medicine in Sport, 3, 287-298.

Trewin, C. B., Hopkins, W. G., \& Pyne, D. B. (2004). Relationship between world-ranking and Olympic performance of swimmers. Journal of Sports Sciences, 22, 339-345.

VanHeest, J. L., Mahnoey, C. E., \& Herr, L. (2004). Characteristic of elite open-water swimmers. The Journal of Strength and Conditioning Research, 18, 302-305.

Winter, E. M, \& Fowler, N. (2009). Exercise defined and quantified according to the Systeme International d'Unites. Journal of Sports Sciences, 27, 447-460. 
Zaryski, C., \& Smith, D. J. (2005). Training principles and issues for ultraendurance athletes. Current Sports Medicine Reports, 4, 165-170. 
Table I. Men's and women's time and speed records and the corresponding years for the 32 km 'English Channel Swim'with the sex difference.

\begin{tabular}{lll}
\cline { 2 - 2 } & $\begin{array}{l}\text { France to } \\
\text { England }\end{array}$ & $\begin{array}{l}\text { England to } \\
\text { France }\end{array}$ \\
\cline { 2 - 3 } Women & $\begin{array}{l}528 \mathrm{~min}(1988) \\
1.01 \mathrm{~m} \cdot \mathrm{s}^{-1}\end{array}$ & $\begin{array}{l}445 \mathrm{~min}(2006) \\
1.20 \mathrm{~m} \cdot \mathrm{s}^{-1}\end{array}$ \\
\hline \multirow{2}{*}{ Men } & $\begin{array}{l}485 \mathrm{~min}(1988) \\
1.10 \mathrm{~m} \cdot \mathrm{s}^{-1}\end{array}$ & $\begin{array}{l}417 \mathrm{~min}(2007) \\
1.28 \mathrm{~m} \cdot \mathrm{s}^{-1}\end{array}$ \\
\hline Difference & $8.9 \%$ & $6.7 \%$ \\
\hline
\end{tabular}




\section{Figure legends}

\section{Figure 1}

Number of 'English Channel Swims' for men and women from 1900 to 2010.

\section{Figure 2}

Most countries represented in 'English Channel Swims', both men and women (i.e. having at least 20 Channel swims), (Panel A). Nationalities of the swimmers with the best annual English Channel swim performances (Panel B).

AUS: Australia, BUL: Bulgaria, CAN: Canada, CZE: Czechoslovakia, EGY: Egypt, FRA: France, GBR: Great Britain, GER: Germany, IND: India, IRL: Ireland, JPN: Japan, MEX: Mexico, NED: Netherlands, RSA: Republic of South Africa, USA: United States of America.

\section{Figure 3}

Changes in the best annual 'English Channel Swim' performance expressed as the swim speed for each sex during the 1900-2010 period. The solid and dotted lines represent the linear regressions for men and women, respectively.

\section{Figure 4}

The mean of the best annual 'English Channel Swim' performances expressed as swim speed did not differ between men and women during the 1900-2010 period $(P>0.05)$. Values are mean $\pm \mathrm{SD}$. 


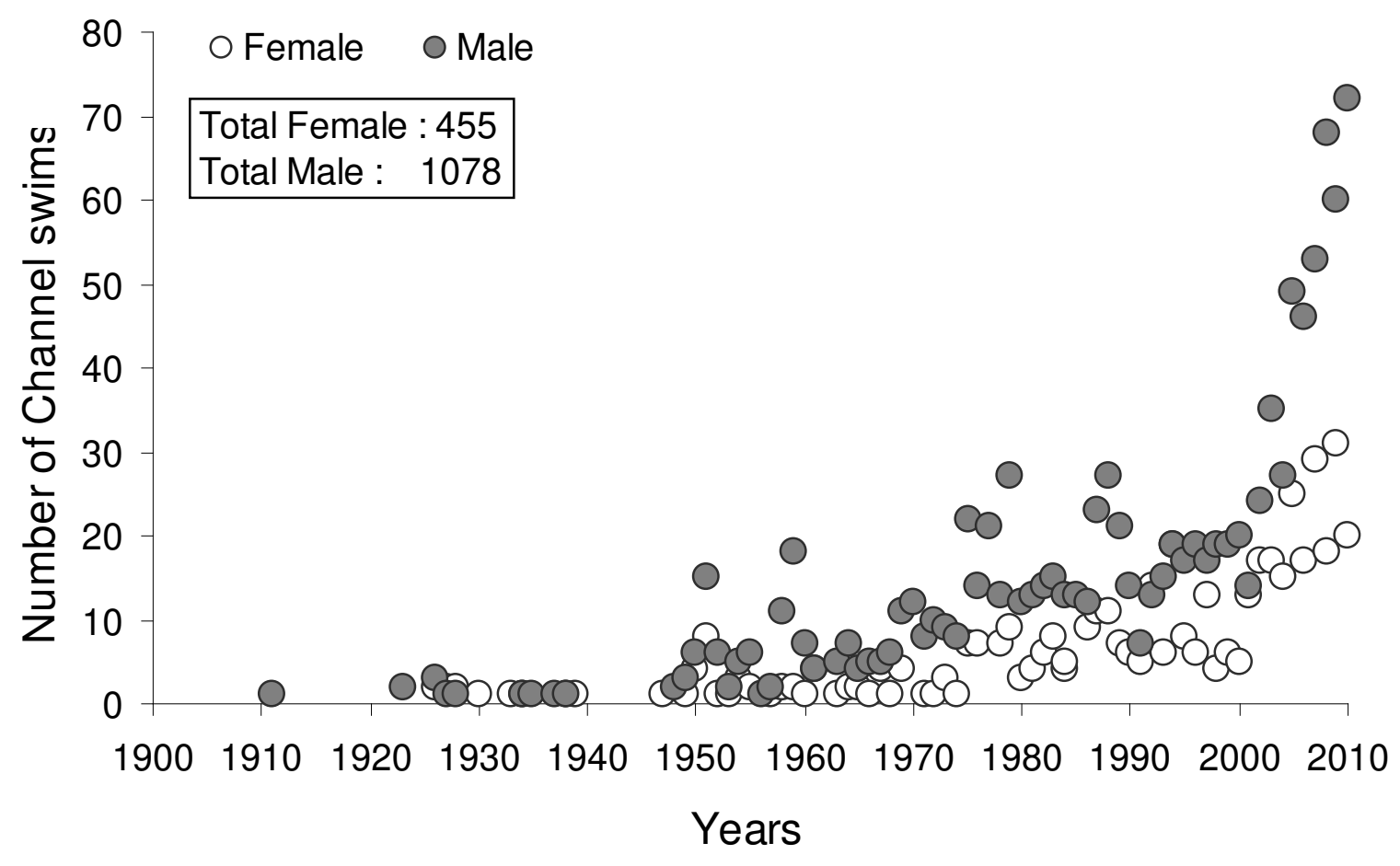

Figure 1 

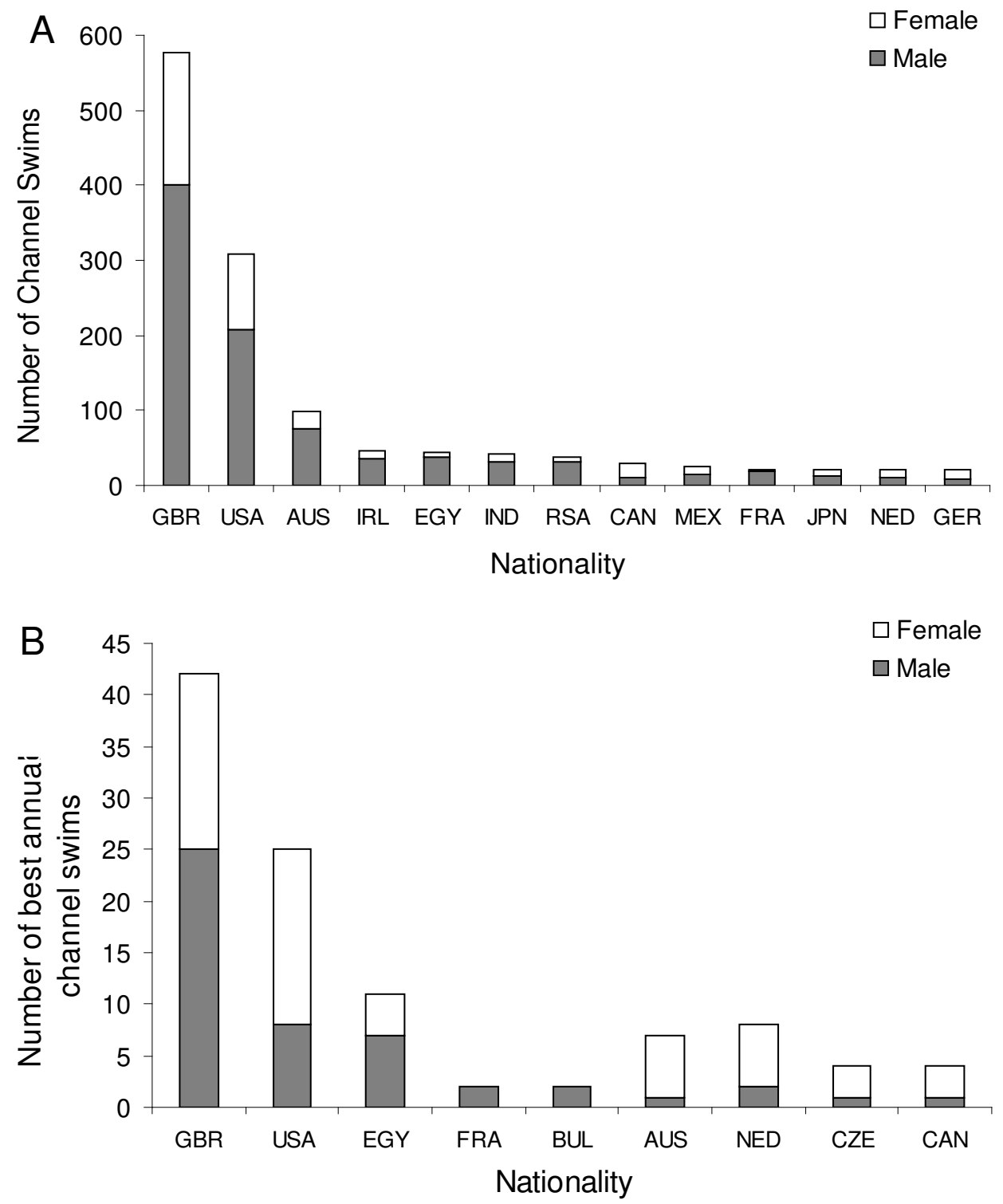

Figure 2 


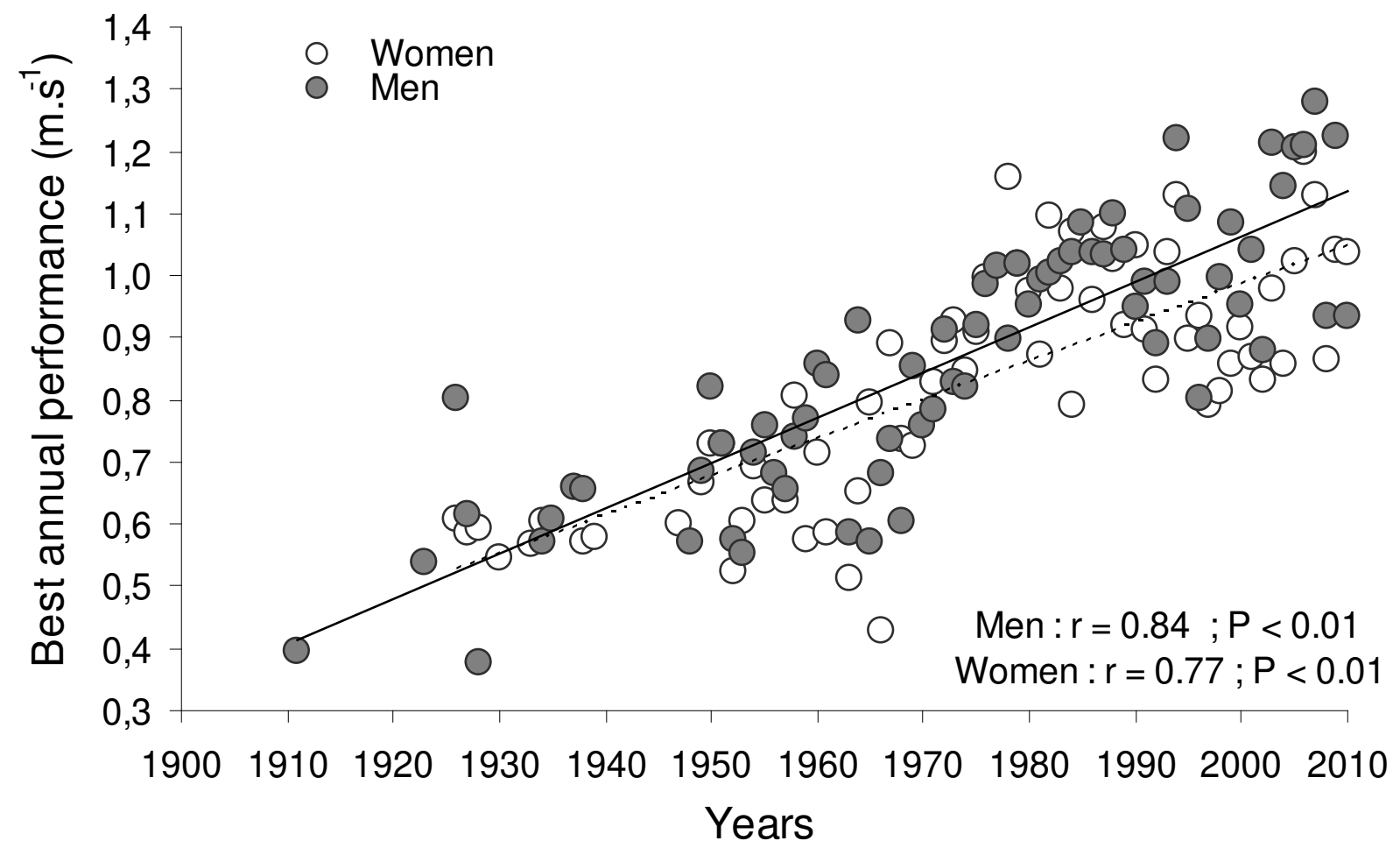

Figure 3 


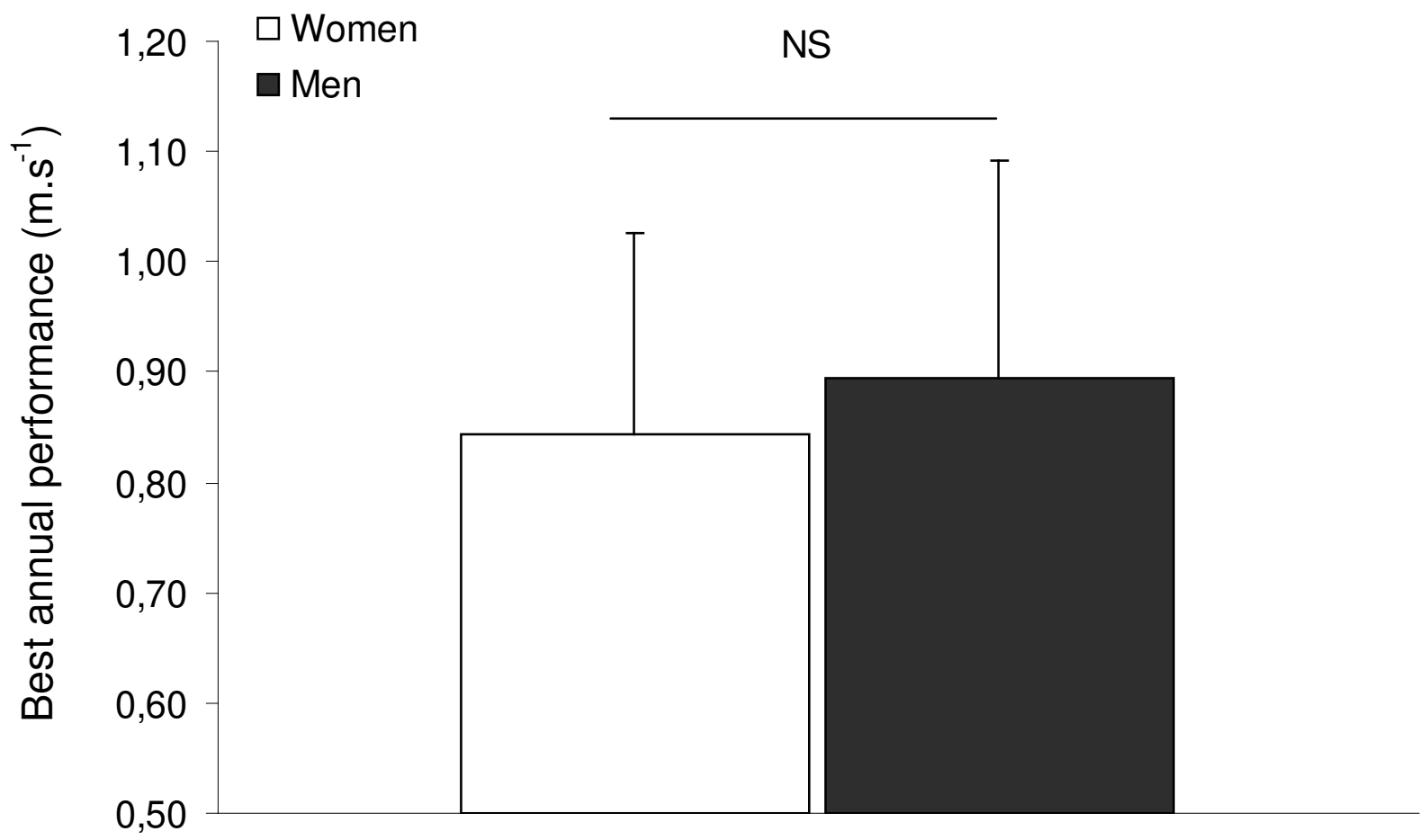

Figure 4 